\title{
EL CONTROL DE LAS COMUNICACIONES MARÍTIMAS: EL CASO PARTICULAR DE LA ADMINISTRACIÓN DE CORREOS DE CÁDIZ ENTRE 1764 Y 1802
}

\author{
Dolores Herrero Gil \\ Universidad de Sevilla
}

\section{RESUMEN}

Las comunicaciones entre España y las Indias, limitadas al medio marítimo, presentaban grandes dificultades. La magnitud del océano suponía un reto al desenvolvimiento de la Administración y resultaba un serio inconveniente para las relaciones comerciales, los contactos personales, y la divulgación de ideas que evolucionaran la vida política, social y cultural. La necesidad de organizar y controlar las comunicaciones desembocó en el establecimiento de un Correo Marítimo estatal durante el reinado de Carlos III. La Administración de Cádiz gestionó determinados aspectos del sistema que analizamos a través de las fuentes existentes en el Archivo General de Indias.

Palabras clave: Cádiz siglo XVIII; Correos Marítimos; Comunicaciones; Transportes de Fondos; Información económica.

\section{ABSTRACT}

Communications between Spain and the West Indies, limited to the maritime transportation, were the source of great difficulties. The magnitude of the ocean was a challenge for the performance of the Administration and meant a serious disadvantage for commercial and personal relationships, and the spreading of ideas which will improve the political, social and cultural life. The need for organizing and controlling the communications culminated in the establishment of a state Maritime Post during the reign of Charles III. The local administration of Cadiz managed different aspects of the system which we analyse through the existing sources in the General Archives of the West Indies.

Key words: $18^{\text {th }}$ c. Cadiz Trade; Maritime Post; Communications; Transport of Funds; Economic information. 


\section{Introducción}

Al principio fue el Mar. La amplitud del océano dificultaba las comunicaciones entre ambos lados del Atlántico, limitadas al medio marítimo. La Administración española nunca anteriormente se había enfrentado a tan dilatados horizontes y el Estado requería de una eficiente transmisión de órdenes y una adecuada recogida de información, necesaria para elaborar sus decisiones ${ }^{1}$. Ninguna de las dos circunstancias se cumplía, en los niveles mínimos exigidos, cuando los colaboradores de Carlos III se esforzaban en conseguir un eficaz funcionamiento de las Instituciones.

A todo ello se refería Pedro Rodríguez de Campomanes ${ }^{2}$ en el informe que en 1762 dirigía a los Directores Generales de Correos proponiendo el establecimiento de un Correo Marítimo Estatal. Hacía referencia a otro anterior, fechado en 1760, en el que había desarrollado sus ideas sobre la construcción y reparación de caminos y sobre el establecimiento de postas bien situadas, continuando el análisis manifestando su preocupación por el contacto marítimo y reconociendo lo acertado del modelo inglés, haciendo referencia al Correo ordinario semanal que los ingleses tenían establecido con sus posesiones septentrionales en América, a través del cual el Gobierno Británico se encontraba con puntualísimas noticias de cuanto ocurría en aquellos parajes, contrariamente a la situación española en que las noticias llegaban tardía y descontroladamente, confiadas a los Registros o Avisos que de tarde en tarde y sin regularidad alguna se despachaban ${ }^{3}$.

Recordaba Campomanes los antecedentes de la situación remontándose al 14 de mayo de 1514 en que fue creado el oficio de Correo Mayor de las Indias. Denunciaba la inoperancia del sistema, no paliado en los últimos años a través del giro de los denominados avisos, embarcaciones gestionadas desde 1720 por el Consulado gaditano ${ }^{4}$. En consecuencia, planteaba la necesidad de conseguir una organización que resultase rentable al Real Erario y no olvidase la importancia de las comunicaciones:

"El pensamiento de entablar un Correo regular para la América no se ha de mirar solo como un proyecto de Hacienda: es una necesidad política para mantener trata con aquellos

\footnotetext{
LÓPEZ BERNAL, José Manuel.: "Las comunicaciones postales en América durante la época colonial (siglos XVI-XVIII)", en El Correo español en América, Madrid, Dirección General del Libro, Archivos y Bibliotecas, Ministerio de Obras Pública, Transporte y Medio Ambiente, 1996, pp. 23-34, 34.

Campomanes tenía en aquel momento los cargos de Asesor General de la Renta y Fiscal del Consejo Real.

AGI (Archivo General de Indias), Correos, 462B. Informe anexo a carta de los Directores Generales de Correos al Excmo. Sr. Ricardo Well, fechada el 19 de julio de 1762. Ver sobre la misma materia: RODRÍGUEZ DE CAMPOMANES, Pedro.: Itinerario Real de los Correos de Postas de dentro y fuera del reyno. Madrid, 1761. (Edición facsímil, 1988). Para conocer aspectos varios del Correo a Indias puede consultarse: BOSE, Walter: "Organización del Correo en España y en las Indias Occidentales. Los Correos Mayores de España, de las Indias, México, Guatemala y Cuba, y los Correos marítimos”, Revista de Correos y Telégrafos, n ${ }^{60}$, 1942, pp. 1.547-1.558; GARAY UNIBASO, Francisco: Los Correos marítimos españoles, Bilbao, Mensajero, 1987; CID RODRÍGUEZ, Rafael: "Los Correos Marítimos a Indias, una empresa de la Ilustración”, Revista de Humanidades, n² 2, 1991, pp. 50-68; "Los Correos Marítimos en las Indias en el siglo XVIII", Rábida, no 10, 1991, pp. 40-51; ALCAZAR, Cayetano: Historia del correo en América (notas y documentos para su estudio), Madrid, Sucesores de Rivedeneyra, S.A., 1920. En cuanto a la organización del Correo Terrestre en España, ver: ARANAZ DEL RIO, Fernando: "Estructura del correo en España durante el primer tercio del siglo XVIII" y JURADO SÁNCHEZ, José: "La red postal de Andalucía en el siglo XVIII", en Actas del I Congreso Internacional de Comunicaciones, Madrid, Ministerio de Obras Públicas, Transporte y Medio Ambiente, 1995, pp. 59-97 y pp. 99-120 respectivamente.

4 En relación al sistema de avisos, el Archivo General de Indias dispone de información para el estudio de dicho período, anterior a la época de Carlos III, en las secciones correspondientes a la Casa de la Contratación, Indiferente General, Contaduría, Arribadas y Consulados. Ver al respecto: LÓPEZ GUTIERREZ, Antonio: "Fuentes para la historia de los Correos Marítimos y Terrestres conservadas en el Archivo General de Indias" en El Correo español...op. cit., pp. 35-50; La Sección de Correos en el Archivo General de Indias, Madrid, Dirección General del Libro, Archivos y Bibliotecas, 1996. También HEREDIA HERRERA, Antonia: Inventario de los fondos de Consulados del Archivo General de Indias, Madrid, Ministerio de Cultura, 1979. Además pueden consultarse: LÓPEZ BERNAL, José Manuel: "Las comunicaciones... op. cit.; "El Consulado de cargadores a Indias de Sevilla y el despacho de avisos en el siglo XVII", Atalaya Filatélica, n 45, julio, 1989, pp. 7-10; "El asiento del marqués de Montesacro de 1707-1708 para el despacho de buques-correo a las Indias", Atalaya Filatélica, no 48, abril, 1990, pp. 7-10 y n 49, julio, 1990, pp. 7-1; HEREDIA HERRERA, Antonia: "Los "avisos", instrumentos de comunicación y de transporte" en Actas del II congreso de Historia de Andalucía y América, Córdoba, Consejería de Cultura y Medio Ambiente de la Junta de Andalucía, 1994, pp. 89-94; "Asiento con el Consulado de Cádiz, en 1720, para el despacho de avisos”, en La burguesía mercantil gaditana (1650-1868), Cádiz, Instituto de Estudios gaditanos, Diputación de Cádiz,1976, pp. 163-172.
} 
vasallos y comunicarles a tiempo las órdenes de la Corte. Al mismo tiempo el Comercio podrá hallar un modelo para no padecer un letargo durante la guerra... ${ }^{\text {" }}$

La Real Orden de 21 de enero de 1764 decidía la formación de una Junta, presidida por el referido Pedro Rodríguez de Campomanes y compuesta por el marqués de Juan de Taso, Ministro del Consejo de Hacienda, los Administradores Generales de Correos, Lázaro Fernández de Angulo y Antonio de la Quadra, los capitanes de navíos Pedro Castejón y Juan Ignacio de Madariaga, y el hermano de éste, Juan Antonio de Madariaga Aróstegui, en calidad de Administrador de Correos de Cádiz. Su objetivo era tratar y consultar a Su Majestad los medios de establecer un Correo reglado de España a las Indias Occidentales. El 16 de febrero se dirigió al marques de Grimaldi la consulta de la Junta con la que se conformó Su Majestad y comenzaron a pasarse las órdenes oportunas ${ }^{6}$.

Tal vez la primera manifestación de la importancia de la plaza de Cádiz podemos encontrarla en el hecho de que su Administrador se viese implicado en la Junta inicial. Y de forma sigilosa. El 27 de enero de 1764, José Larrarte, agente del Consulado del Comercio gaditano en Madrid, alertaba de la creación de la misma y citaba, por rumores, los posibles nombres de sus integrantes, que permanecían en el anonimato ${ }^{7}$. También proporcionaba algún dato sobre sus temidas intenciones que tanto vulnerarían el sistema de asiento existente, posiblemente anulándolo. Durante los meses siguientes, y continuamente demandado por un crecientemente preocupado Consulado, no escatimó medios para conseguir información: regalos con matices de sobornos, asistencias a fiestas, encuentros forzados con hombres importantes... Era comentario, en los círculos mejor informados, que no avanzaba el estudio, que existía un cierto desconcierto. Por lo tanto, se decidía contraatacar, mientras hubiese tiempo para ello, con un Memorial del Consulado que adjuntaba una propuesta de servicio de doce barcos, en vez de los ocho existentes. Pero nada consiguió frenar el inicio de la nueva Organización, aunque en un desesperado intento se otorgaran poderes a un hijo de Larrarte, autorizándolo a que prometiera correr con todos los gastos que hubiesen podido originarse en los estudios acometidos hasta aquel momento, si se reconsideraba la situación. Ningún contacto resultó válido, no se aceptó ninguna promesa, ni se torcieron las voluntades ${ }^{8}$. Para el informador del Consulado quedaba muy claro que Arriaga, Ministro de Marina, no había intervenido en absoluto en el proceso y que este se gestó por el Ministro de Estado, Grimaldi, previa aceptación de las ideas anteriormente manifestadas por Pedro Rodríguez de Campomanes?

\section{El Correo Marítimo Estatal}

Precisamente Grimaldi era el principal receptor del extenso informe de Campomanes al que nos hemos referido anteriormente. En su puesto de Primer Secretario de Estado asumía desde 1747 la Superintendencia de Correos y Postas ${ }^{10}$. Tras amplios debates, y superada la preceptiva consulta al Monarca, se emitía el 24 de agosto de 1764 el Reglamento provisional del Correo Marítimo de España y sus Indias

\footnotetext{
AGI, Correos, 462B. Informe de Pedro Rodríguez de Campomanes.

AGI, Correos, 450B. Informe de Don Juan de Daragorri en 1766.

AGI, Consulados, 218. No citaba a Juan Antonio de Madariaga, cuya asistencia conocemos por otra documentación, ya reseñada. La confirma el hecho de que la correspondencia de la Administración de Cádiz durante esos meses aparece firmada por el Oficial Mayor, Manuel Bazquez, en ausencia de Madariaga, al que suponemos en Madrid.

\& Ibídem. El 9 de agosto de 1764 se publicó en el Consejo de Indias el primer Decreto de Su Majestad tocante a los Correos Marítimos. Se recibió "con respeto y sumisión”, acordándose pasase a los fiscales...

$9 \quad$ Ibídem. Correspondencia entre José Larrarte y los Señores Prior y Cónsules del Consulado de Cádiz.

10 AGI, Correos, 428A. Grimaldi, antes de tomar ninguna decisión, demandó que se le informara sobre varias cuestiones: $1^{\circ}$ - Especies de embarcaciones que eran convenientes para conducir y retornar la valija, su buque y la tripulación; $2^{\circ}$ - Cuantos barcos serían necesarios para que el correo pudiese partir hacia América cada mes, y el de América se recibiese en el mismo espacio de tiempo en España; $3^{\circ}$ - Que coste tendría cada una de estas embarcaciones, y si debían construirse de cuenta del Rey, y donde, o comprar hechas, y donde; $4^{\circ}$ - Cuales eran los parajes de España de los que debían salir para estar más libres en tiempo de Guerra, y menos expuestas a los Moros; $5^{\circ}$ - Igualmente, cuales eran los puertos de América a los que debían ir para llevar la correspondencia general de España, y cuanto tiempo tardarían en un viaje regular; $6^{\circ}$ - Que tipo de embarcaciones pequeñas se usaban en la América del Mar del Norte desde el Orinoco al Golfo Mexicano que pudiesen servir para hacer circular la correspondencia a las Islas y Tierra Firme de toda la América; $7^{\circ}$ - Que frutos, en especial harinas y vino, podrían llevar por lastre, y cuanto importaría su flete. Que pasaje podría llevar, cuanto podría cobrarse por ello, y cuanto importarían los víveres para la ida y la vuelta.
} 
Occidentales ${ }^{11}$ por el que se creaba la llamada Carrera de la Habana. En el mismo se decidía el envío de un barco mensual hacía el citado destino, teniendo como origen el puerto de La Coruña ${ }^{12}$. Se definían los puntos que deberían tocarse en la isla de Cuba, desde la que partiría la correspondencia hacía otros destinos en el continente por medio de balandras y, desde estos, se distribuirían utilizando el transporte terrestre ${ }^{13}$.

En 1767 se decidía como más operativa la división en dos Carreras, con una segunda hacia Buenos Aires ${ }^{14} q u e$ no alteraba la elección, como origen, del puerto peninsular aunque sí cambiaba, y mucho, el esquema inicial en el continente americano ${ }^{15}$. En este caso los barcos saldrían cada tres meses, hasta que el 7 de abril de 1771 se ampliaba el servicio a uno cada dos meses. El 26 de enero de 1777 se emitía el Reglamento definitivo para el buen gobierno de los Correos Marítimos y se enviaba a los destinos afectados, para su exacto cumplimiento ${ }^{16}$. En 1778 se proponía el envío de un paquebote mensual a Canarias, suprimiéndolo en 1793 por costoso e innecesario, toda vez que los que marchaban a la Habana podían cubrir este destino al paso ${ }^{17}$. Y también, durante un tiempo, se cubrió una Carrera con Falmouth, que había tenido precedente en el siglo XVII y que, en esta nueva época, comenzaba el 2 de julio de 1793, hasta que se interrumpía en 1797 por la situación de guerra con Inglaterra ${ }^{18}$.

Durante los años 1765, 1767 y 1768 se fueron incorporando a la Corona los Oficios de Correos que estaban en América en manos de particulares ${ }^{19}$, de forma que la distribución terrestre en aquel continente pasaba a ser responsabilidad del Estado. El servicio continuó paulatinamente perfeccionando su organización interna, destacando el papel de las Administraciones peninsulares y las ultramarinas ${ }^{20}$.

Entre las primeras tenían especial importancia la de La Coruña, cabecera del tráfico de los paquebotes correos, y la de Bilbao, que se significó por su labor de construcción y carena de los buques ${ }^{21}$. En cuanto a la gaditana presenta especiales características. En primer lugar porque a través de su puerto llegaron y partieron muchas de las cartas particulares y muchos de los duplicados que, por vía reservada, se enviaban de documentos oficiales. En segundo lugar, porque las remesas de efectivo se remitían en gran parte para Cádiz, porque Cádiz era la cabecera del comercio. Por ello, aunque se utilizaran los barcos Correos para transportar caudales a La Coruña, la Administración gaditana se veía implicada en la percepción y reparto de los mismos, aparte de las remesas que al puerto de Cádiz, en barcos mercantes o de guerra, llegaban con destino a la Tesorería de la Renta, de parte de las Administraciones americanas. En tercero, porque Cádiz era un lugar privilegiado para solucionar problemas financieros y para recabar información variopinta, necesaria para la mejor gestión global de la organización.

El artículo 19 del Reglamento Provisional de 1764 especificaba que toda embarcación mercante o de guerra debería admitir los cajones de Correos sin ningún cargo por fletes. Con ello quedaba Cádiz inserta de forma muy significativa en el funcionamiento del servicio, dado el gran número de embarcaciones

\footnotetext{
11 AGI, Correos, 484A. En el proyecto legislativo se explica extensamente la situación anterior y los motivos del cambio de sistema. El artículo 22-2 manifiesta la importancia concedida a las comunicaciones: "Nadie podrá detener Embarcación alguna del Correo, ni impedirle su viage regular, aunque sea motivando causas del servicio del Rey; pues ninguna ay mayor que mantener el regular curso de la correspondencia de España a Indias, y su retorno."

12 Los barcos saldrían el día primero de cada mes. Entre otros autores que tratan la ubicación en La Coruña, puede consultarse a LAGO MARTINEZ, Manuel: "La Coruña en los Correos marítimos de España", Porteo, año 1, nº 1,1976, 18-20.

13 El 25 de enero de 1796 el Príncipe de la Paz aceptaba un cambio en el rumbo, según la propuesta de Don Antonio de Albuerne, llegando hasta Veracruz y eliminando el sistema de balandras desde la Habana. AGI, Correos, 462B.

${ }_{14}$ El gobernador, Cevallos, que se hizo cargo de la primera distribución, tenía experiencia. Antes del 27 de diciembre de 1763, en que la colonia de Sacramento había sido devuelta a los portugueses, había organizado un interesante sistema de comunicación postal. En BOSE, Walter: "El correo a las misiones (1757-62)", Centro de Estudios Históricos, n 3, pp. 49-68.

${ }_{15} \mathrm{Al}$ respecto ver LÓPEZ BERNAL, José Manuel.: "Las comunicaciones..." op.cit. pp. 32-33. También el mismo autor aporta algunos datos sobre correspondencia hacia Buenos Aires en embarcaciones desde Cádiz en LÓPEZ BERNAL, José Manuel: "El Correo Marítimo entre Cádiz y Buenos Aires (1764-1767): la alternativa de los navíos de Registro". Separata de Atalaya Filatélica nº 76, 1997.

16 AGNA (Archivo General de la Nación Argentina), Sala IX, 8,10,6: "Reglas que en ejecución del Artículo 12, del Título I, Tratado

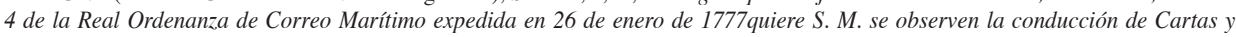
Pliegos..."

17 AGI, Correos, 462B. Informe efectuado el 5 de marzo de 1803.

18 AGI, Correos, 471B.

19 COLOMAR ALBAJAR, María Antonia (1996): “Catálogo de la Exposición, Selección y Catalogación”, en El Correo español... op.cit., pp. 53-116, p. 69.

20 Ibídem, p. 41.

21 De ambas administraciones existen cuantiosas noticias en la Sección de Correos del Archivo General de Indias.
} 
que utilizaban su puerto, convirtiéndose en centro de recepción y envío de correspondencia. Hemos analizado su actividad hasta el año 1802, en que se encarga a la Real Armada el funcionamiento de los Correos marítimos ${ }^{22}$. Durante esos años la Administración dependió de dos sujetos de la familia Madariaga, padre e hijo, que son objeto de nuestra investigación en estas y otras actividades.

\section{La Administración de Correos de Cádiz: algunos datos generales}

El Administrador de Correos de Cádiz en 1764 era Juan Antonio de Madariaga Aróstegui. Nacido el 16 de Julio de 1721 en la ante iglesia de Axpe de Busturia, perteneciente al señorío de Vizcaya, había contraído matrimonio en La Graña el 13 de Noviembre de 1752, trasladándose a Cádiz el siguiente año, ostentando el cargo de Oficial de la Contaduría Principal de Marina. El 3 de Febrero de 1755 se le encomendaba el Oficio de Correos y Postas de la Ciudad de Cádiz, y a partir de 1764 se encargó, además, de los derechos y patrimonios de la Casa Ducal de Arcos en la Real Isla de León ${ }^{23}$.

El primero de estos cargos tenía especial significado. Aparte del objetivo primordial del Estado de conseguir una eficaz transmisión de órdenes, el aporte de datos que recibía el hombre de negocios a través de su correspondencia resultaba vital para el ejercicio de la actividad mercantil, constituyendo el canal de mayor significación para el conocimiento de los hechos que posibilitaran la planificación de sus proyectos. Por tanto, en una plaza como la ciudad de Cádiz tendría ese puesto una singular relevancia. Juan Antonio lo desarrolló hasta el año 1786, en que pasaba a ser ejercido por su hijo Juan Felipe de Madariaga Arzueta. Durante estos años consiguió ser distinguido con el hábito de Caballero de Santiago en $1758^{24}$ y con el título de marqués de Casa Alta el 16 de Febrero de $1775^{25}$.

Su sucesor, nacido en la Graña en el año 1753, contrajo matrimonio en 1771 con Petronila de Llano Fernández, hija de Francisco de Llano San Ginés ${ }^{26}$, conde de Torre Alegre, llegando a ostentar los títulos de su padre y de su suegro, además de conseguir el reconocimiento del monarca con la concesión, en 1789, de la Cruz de Carlos III' ${ }^{27}$. Gestionó la Administración de Correos de Cádiz entre los años 1787 a $1798^{28}$, en que pasa a figurar como titular Antonio Ruiz de Mendoza hasta el fin del período considerado.

Pronto se muestran las disposiciones que van tomando desde la estafeta de Correos para el funcionamiento del nuevo sistema de comunicación marítima. Se recibieron los sellos con las inscripciones de España e Indias, se decidían las tarifas que debían aplicarse, se estudiaba la conveniencia de emitir un Bando contra el fraude, se pedían instrucciones sobre las competencias a desarrollar por la Casa de la Contratación y se procede al control de la Compañía de la Habana y la de Caracas, evitando el transporte ilícito de correspondencia a través de las mismas ${ }^{29}$.

El circuito se perfiló paulatinamente de forma que, a la llegada de un navío portador de correspondencia, se procedía a un primer envío, a la ligera, con la documentación para el Bailio ${ }^{30}$. Posteriormente se originaba un segundo despacho con la correspondencia oficial no tan urgente junto a la de particulares residentes en la Corte y en otros Reinos de la península. También se daba cuenta de lo llegado para Cádiz y los cuatro Reinos de Andalucía, que se distribuía directamente a través de la

\footnotetext{
22 AGI, Correos, 462B. Godoy a Cevallos, 6 abril 1802. Propone el 1 de junio para comenzar las nuevas expediciones. Sobre el paso a la Armada, puede consultarse a CID RODRÍGUEZ, Rafael y LOPEZ BERNAL, José Manuel: "El declive de los Correos Marítimos de Indias y su incorporación a la Real Armada", Revista de Humanidades, n 3, 1992, pp. 49-61.

23 TORREJÓN CHÁVEZ, Juan: "Burgueses gaditanos en busca del titulo nobiliario: los casos de Juan Antonio de Madariaga, y de José Rodríguez", en A. García-Baquero (ed.):" La Burguesía de negocios en la Andalucía de la Ilustración" Cádiz, Diputación Provincial de Cádiz, 1991, tomo II, pp. 347-352, p. 348.

24 AHN (Archivo Histórico nacional), Órdenes Militares, Santiago, Caja 902, Expediente 4.744.

25 AHN Consejos. Títulos del Reino. Libro 628 y Consejos, $11.760 \mathrm{n}^{\circ}$ 16; Archivo General de Simancas (A.G.S.), Gracia y Justicia, 872 y Dirección General del Tesoro, Mercedes de Cámara, Inventario 3, legajo 34.

26 Uno de los socios de la prestigiosa compañía comercial y naviera Ustáriz y San Ginés.

27 AHN Estado, Expediente 341, Orden Carlos III.

${ }_{28}$ AGI Correos 370A, 370B, 371 a. Durante algunos períodos de los años 1777, 1787, 1788, 1789 y 1790 figura como Administrador interino Juan Ángel de Enderica. El año 1789 aparece Manuel Mollinedo, Oficial Mayor, como responsable por enfermedad del Administrador interino.

29 AGI Correos, 369A.

30 Llegaban dirigidas al Presidente de la Casa de la Contratación, que organizaba su envío a Madrid.
} 
propia estafeta gaditana y de las administraciones de Sevilla, Málaga y Granada. Otro envío se formaba con las cartas traídas por varios sujetos, llegadas bajo sus cubiertas, siendo entregadas por estos en el Oficio de Correos $^{31}$, más las conseguidas por el Comandante en la correspondiente visita de inspección y las devueltas por el Presidente de la Casa de la Contratación por haber venido bajo sus cubiertas pero entender que no le correspondía distribuirlas.

\section{Salida y llegada de la correspondencia a través del puerto gaditano.}

La información de la que hemos podido disponer no es homogénea. Las salidas de correspondencia se constatan en dos tipos de documentos: la razón del valor de las cartas que se remiten en un determinado barco hacia varios destinos y las llamadas guías, en la que se certifica al Administrador del lugar de destino la correspondencia que viaja hacia el mismo y la embarcación que la transporta. El cuadro estadístico correspondiente a los años 1779 a $1792^{32}$ recoge los datos de un total de 394 barcos y expresa, en reales de plata fuerte, el valor que corresponde a dichos envíos. El máximo se produce en el ejercicio de 1784, decreciendo paulatinamente, sin recuperaciones.

Los tres puertos principales a los que se dirigía la correspondencia enviada desde Cádiz eran La Habana, Veracruz y México, que representan un $77 \%$ del total, existiendo veintidós destinos, de muy diferentes importancias. Junto a ellos deben considerarse, por su significación, los montantes que resultan de la recaudación de la correspondencia destinada a Caracas, Lima, Guatemala, Cartagena, La Guaira o Buenos Aires, debiendo igualmente mencionar la que viajaba hacía Manila, que alcanza un total de 8.703 reales.

El número de cartas (sencillas, dobles y triples), enviadas durante los años a que nos venimos refiriendo, alcanza la cifra de 97.521 unidades, que pagaron un importe de 334.960 reales de plata fuertes, es decir, un $72 \%$ de la recaudación a la que hicimos anterior referencia.

Por otra parte, existía un conjunto de cartas, denominadas "de peso", que eran en realidad pliegos o paquetes, que originaron un $28 \%$ de los ingresos, con un montante total de 128.503 reales de plata doble. ${ }^{33}$ Pero en este caso desconocemos su número, puesto que no se tarifaban por unidad, sino por las onzas que arrojasen en su peso ${ }^{34}$.

En cuanto a la documentación disponible de las cartas llegadas a Cádiz, algo distinta de la anteriormente citada y mucho más escasa, hace mención al nombre del barco que las portaba, la fecha en que tocaba puerto, su nacionalidad, su característica de guerra o mercante y el importe de la correspondencia. En algunos casos se hacía expresa referencia a que, además del importe reseñado, debía añadirse el que correspondía a los Pliegos y Cartas que vinieran para distintos Ministros del Estado. Todo ello expresado en reales de vellón. Hemos localizado los datos referentes a tres ejercicios, que corresponden a un total de 299 barcos, muchos de ellos de otras nacionalidades, principalmente suecos, genoveses y franceses ${ }^{35}$.

Las guías son similares a las que se generaban en las salidas de correspondencia ${ }^{36}$. Desde el punto de origen, y firmadas por el Administrador, especificaban el número de cartas, divididas en sencillas y de 6, 8, 10,12 o 14 adarmes destinadas a Cádiz. También se reseñaba en el documento el peso de los pliegos o paquetes, las cartas que viajaban certificadas, de las que se solicitaba recibo, y las que lo hicieron francas, o pagadas en origen. También son similares los estados o razones que manifiestan los valores de la correspondencia llegada en una determinada nave, correspondiente a varios destinos

\footnotetext{
31 AGI, Correos, 369A. Carta fechada el 8 de enero de 1765 de Madariaga a los Directores Generales de la Renta. Ha recibido instrucción de que debe abonar a cualquier persona a quienes vengan cartas de Indias bajo sus cubiertas el importe de aquellas que sean para otros individuos, siempre que los interesados, o personas de su confianza, abran los pliegos en su presencia.

32 Cuadro I : Los importes necesarios para su elaboración han sido extraídos de AGI Correos, 372.

33 Cuadro II. Elaboración propia con datos extraídos de AGI, Correos, 372.

34 AGI, Correos, 484A. Según el articulo 18 del Reglamento Provisional las tarifas a aplicar serían las que siguen: carta sencilla hasta media onza, 4 reales de vellón en España y 3 de plata fuerte en Indias. Carta doble, de media onza a tres cuartos, 9 y 5 , respectivamente. Carta triple, 12 de vellón y 7 plata. Paquetes 25 reales de vellón por onza (con equivalencia de 10 reales de plata fuerte) en Indias y de 16 reales de vellón en España por similar peso.

35 Cuadro III. Elaboración propia con datos de AGI, Correos, 372.

36 Las de llegada se han localizado en AGI, Correos, 371B y Correos, 463A y B.
} 


\begin{tabular}{|c|c|c|c|c|c|c|c|c|c|c|c|c|c|c|c|}
\hline \multicolumn{16}{|c|}{ CUADRO I: IMPORTE RECUDADO POR CORRESPONDENCIA ENVIADA } \\
\hline Destino/ año & 1779 & 1780 & 1781 & 1782 & 1783 & 1784 & 1785 & 1786 & 1787 & 1788 & 1789 & 1790 & 1791 & 1792 & $\begin{array}{l}\text { R. Plata } \\
\text { fuertes. }\end{array}$ \\
\hline B. Aires & & & & 3.572 & 3.703 & & & 666 & & & & & & & 7.941 \\
\hline Campeche & & & & & 18 & 154 & 409 & 218 & 484 & 456 & & & & & 1.739 \\
\hline Caracas & & 736 & 320 & 1.006 & 1.366 & 6.321 & 5.364 & 5.351 & 5.192 & & & & & & 25.656 \\
\hline Cartagena & 206 & & 1.325 & 2.115 & 3.041 & 1.005 & 1.124 & 118 & 506 & 193 & & & & 592 & 10.225 \\
\hline Chile & 25 & & & 444 & 576 & 51 & & 315 & & & & & & & 1.411 \\
\hline S. Domingo & & & 110 & 252 & & 82 & & 26 & & & & & & & 470 \\
\hline Guaira & & 377 & & 263 & 373 & 2.742 & 2.386 & 2.508 & 1.652 & & & & & & 10.301 \\
\hline Guatemala & 545 & & & & 766 & 888 & 4.498 & 5.287 & 3.027 & 1.161 & & & & & 16.172 \\
\hline Guayana & & & & & & & & 45 & & & & & & & 45 \\
\hline Habana & 1.497 & 849 & 5.456 & 18.369 & 16.517 & 15.934 & 14.641 & 7.686 & 8.375 & 8.287 & 520 & 258 & 307 & 1.072 & 99.768 \\
\hline Honduras & 44 & & & & & & & & & & & & & & 44 \\
\hline Lima & 2.516 & & 1.256 & 3.145 & 5.781 & 4.343 & 274 & 104 & 143 & & & & & 366 & 17.928 \\
\hline Manila & & & & & 597 & & 1.216 & 3.450 & 1.030 & 2.410 & & & & & 8.703 \\
\hline Maracaibo & & & & & 255 & & & & & & & & & & 255 \\
\hline México & 1.010 & 4.716 & 1.794 & 8.914 & 12.006 & 11.363 & 9.219 & 9.027 & 7.970 & 7.731 & 1.652 & 1.070 & 865 & 216 & 77.553 \\
\hline Montevideo & & & & 617 & 561 & & & 315 & & & & & & & 1.493 \\
\hline N.Orleans & & & & & & & & & & & & 21 & & & 21 \\
\hline Omoa & & & & & 71 & & & & & & & & & & 71 \\
\hline P.Rico & 20 & 165 & 190 & 160 & & 190 & 176 & 96 & 38 & & & & & 55 & 1.090 \\
\hline Quito & & & 184 & 65 & 126 & 80 & & & & & & & & & 455 \\
\hline Trinidad & & & & & & & 108 & & & & & & & 39 & 147 \\
\hline Veracruz & 4.465 & 12.877 & 2.645 & 18.239 & 28.726 & 25.372 & 23.577 & 19.475 & 17.860 & 18.933 & 4.624 & 1.925 & 1.770 & 1.487 & 181.975 \\
\hline TOTALES & 10.328 & 19.720 & 13.280 & 57.161 & 74.483 & 68.525 & 62.992 & 54.687 & 46.277 & 39.171 & 6.796 & 3.274 & 2.942 & 3.827 & 463.463 \\
\hline
\end{tabular}

peninsulares. La que debía hacerse seguir fuera de la plaza generaba otra documentación en la que se especificaba el número de cartas y los importes que correspondían a la Administración gaditana en pago a sus servicios.

\section{Los caudales de América: llegados a Cádiz}

Más interesante que el tráfico de correspondencia resulta el estudio de las remesas monetarias. La llegada de un montante de caudales a Cádiz, procedente de la recaudación de las Administraciones americanas, y por tanto de cuenta de la Renta de Correos, originaba un circuito de recepción y envío a Madrid, a la Tesorería de la Dirección General de la Renta ${ }^{37}$. En ocasiones se prefería mantener el efectivo en la Administración de la ciudad, puesto que si se debían pagar en ella cantidades llegadas a La Coruña en barcos de Correos, con destino a particulares gaditanos, era conveniente que en esta Plaza hubiese posibilidad de cubrir estas contingencias, evitando el traslado desde tan lejano puerto. Normalmente se pedían instrucciones para saber lo que era más adecuado en cada momento.

\footnotetext{
37 El 10 de enero de 1786, recientemente ocupado su cargo, solicitaba el conde de Torre Alegre, Felipe de Madariaga, una remuneración anual por el manejo de caudales venidos de América.
} 


\begin{tabular}{|r|r|r|r|r|r|}
\hline \multicolumn{7}{|c|}{ CUADRO II: datos varios de envíos } \\
\hline Año & $\begin{array}{c}\mathbf{N}^{\mathbf{0}} \mathbf{d e} \\
\text { cartas }\end{array}$ & $\begin{array}{c}\text { Recaudado } \\
\text { Cartas }\end{array}$ & $\begin{array}{c}\text { Recaudado } \\
\text { Paquetes }\end{array}$ & $\begin{array}{c}\text { Total } \\
\text { R. Plata fuerte }\end{array}$ & $\mathbf{N}^{\mathbf{0}}$ de barcos \\
\hline $\mathbf{1 7 7 9}$ & 2.314 & 6.412 & 3.916 & 10.328 & 17 \\
\hline $\mathbf{1 7 8 0}$ & 4.436 & 12.193 & 7.527 & 19.720 & 11 \\
\hline $\mathbf{1 7 8 1}$ & 2.727 & 10.048 & 3232 & 13.280 & 2 \\
\hline $\mathbf{1 7 8 2}$ & 11.762 & 40.932 & 16.229 & 57.161 & 33 \\
\hline $\mathbf{1 7 8 3}$ & 17.699 & 54.242 & 20.241 & 74.483 & 63 \\
\hline $\mathbf{1 7 8 4}$ & 14.012 & 50.201 & 18.324 & 68.525 & 59 \\
\hline $\mathbf{1 7 8 5}$ & 12.828 & 45.963 & 17.029 & 62.992 & 64 \\
\hline $\mathbf{1 7 8 6}$ & 10.428 & 37.880 & 16.807 & 54.687 & 50 \\
\hline $\mathbf{1 7 8 7}$ & 9.459 & 34.744 & 11.533 & 46.277 & 41 \\
\hline $\mathbf{1 7 8 8}$ & 8.392 & 29.957 & 9.214 & 39.171 & 34 \\
\hline $\mathbf{1 7 8 9}$ & 1.463 & 5.198 & 1.598 & 6.796 & 4 \\
\hline $\mathbf{1 7 9 0}$ & 597 & 2.073 & 1.201 & 3.274 & 4 \\
\hline $\mathbf{1 7 9 1}$ & 617 & 2.115 & 827 & 2.942 & 3 \\
\hline $\mathbf{1 7 9 2}$ & 787 & 3.002 & 825 & 3.827 & 9 \\
\hline Totales & $\mathbf{9 7 . 5 2 1}$ & $\mathbf{3 3 4 . 9 6 0}$ & $\mathbf{1 2 8 . 5 0 3}$ & $\mathbf{4 6 3 . 4 6 3}$ & $\mathbf{3 9 4}$ \\
\hline
\end{tabular}

Debemos aclarar que, alternativamente a dichos envíos, existía la posibilidad de comprar letras de cambio por importe aproximado al efectivo llegado, enviándolas a la Tesorería para su cobro en Madrid. A estas utilizaciones de productos financieros nos referiremos extensamente más adelante considerándolo un elemento favorable, si se compara con el peligroso y caro traslado de efectivo, y de singular importancia en Cádiz, centro financiero por excelencia. De igual forma, no siempre llegaba de América el importe recaudado en efectivo. Desde la Administración de Caracas y por parte de su responsable Francisco Antonio de Quintana, era habitual el envío de cacao, que resultaba más rentable ${ }^{38}$. En Cádiz se recibía el conocimiento de embarque por cuenta de la Renta y, una vez recogida la mercancía, se procedía a su venta y al envío del resultante, deducidos los gastos.

\section{Los caudales de América: llegados a La Coruña}

La importancia receptora de recursos económicos de la ciudad de Cádiz resulta evidente a través de la documentación existente, que proporciona datos sobre las cantidades llegadas a La Coruña durante los años 1775 a 1779. Refiriéndonos a la Carrera de Buenos Aires, observamos que los fondos monetarios llegaban a La Coruña destinados exclusivamente a Cádiz y Madrid, resultando la estadística rotunda: el $86 \%$ de los caudales se destinaban a la Administración gaditana y tan sólo el 14\% de los mismos deberían ser entregados en Madrid ${ }^{39}$.

Durante algún tiempo los comerciantes americanos manifestaron su preferencia por esperar la salida de un barco mercante o de guerra hacia Cádiz, aunque saliera dos meses después del paquebote de Correos, para enviar sus remesas de efectivo. Dicha actuación era debida a que el traslado de los fondos entre La Coruña y Cádiz no se realizaba con la eficacia deseable ${ }^{40}$. Para evitar esta pérdida de

38 Un envío de 9.419 reales de plata fuerte en cacao generaba una diferencia a favor de unos cuatro mil quinientos reales de vellón. AGI, Correos, 369B.

39 Cuadro IV. Los datos necesarios para elaborar la Tabla de entradas de caudales han sido localizados en AGI, Correos, 373A y B.

40 AGI, Correos, 373A. 


\begin{tabular}{|c|c|c|}
\hline \multicolumn{3}{|c|}{ CUADRO III: llegada correspondencia } \\
\hline Año & Reales de vellón & Número de barcos \\
\hline & (llegadas) & (llegadas) \\
\hline $\mathbf{1 7 8 8}$ & 202.326 & 55 \\
\hline $\mathbf{1 7 8 7}$ & 287.265 & 119 \\
\hline $\mathbf{1 7 8 6}$ & 247.569 & 125 \\
\hline Total & $\mathbf{7 3 7 . 1 6 0}$ & $\mathbf{2 9 9}$ \\
\hline
\end{tabular}

usuarios, que se consideraba perjudicial para el real Erario ${ }^{41}$, se propuso que los afectados recibieran el dinero anticipadamente, sin esperar el traslado de los caudales, con algún pequeño descuento ${ }^{42}$. A la Administración gaditana se enviaba la copia, certificada por el Contador general de la Renta, de la liquidación, hecha en La Coruña, de las partidas registradas en un barco determinado, adjuntando, si era necesario, letra o pagaré para que pudiesen conseguir el efectivo y procedieran a los pagos inmediatos. El método resultó muy aplaudido por los comerciantes, que comparaban la diligencia con la que se producía el cobro con las demoras que sufrían cuando llegaban las remesas efectivas a Cádiz, en barcos ajenos al servicio de Correos, es decir mercantes o de guerra, debiendo esperar la orden de la Corte para la entrega de las mismas y teniendo que efectuar muchas y prolijas diligencias, en lo que se entretenían varios días. Para percibir dichos anticipos, los interesados debían aportar los conocimiento de las partidas que vinieran a su consignación ${ }^{43}$.

En otras ocasiones el problema residía en la falta de tesorería, sobre todo si coincidía con fechas de cierres de ejercicios, que demoraban las llegadas desde Madrid ${ }^{44}$. En estos casos solía recurrirse a conseguir las cantidades necesarias de comerciantes gaditanos que desearan colocar sus puntas de tesorería en transacciones de garantía absoluta, procediendo a la entrega de letras giradas a la vista contra el Tesorero de la Renta.

Todos los ajustes que lentamente se realizan evidencian el principal problema, que no es otro que el traslado del efectivo. En 1777 se decide enviar las remesas llegadas a La Coruña con la utilización de arrieros o conductores de plata ${ }^{45}$. Los gestores de la ciudad especificaron que debía organizarse el sistema de acuerdo con el antecedente modelo gaditano: "como se ejecuta en Cádiz..."

No obstante, la solución definitiva llegaba en 1785 cuando el Banco de San Carlos ${ }^{47}$ hacía una propuesta para tomar en La Coruña todas las cantidades que llegasen sobre ese puerto haciendo entrega

\footnotetext{
${ }^{41}$ AGI, Correos, 373B. La conducción de caudales proporcionaba apetecibles ingresos. La fragata el Tucumán, que vino de Montevideo el 27 de septiembre de 1778, tiene desglosados los gastos: 9\% a la Aduana por el Real Proyecto y Guardacosta. Un uno por mil al Almirantazgo. El 1\% al Consulado, 1/4\% para la catedral de Cádiz, por Real Orden de 17 de agosto de 1778. Otro 1/2\% al capitán por su Maestría. Y un $2 \%$ a la Renta por razón de su flete. En total, 12 3\%4 \% más 1 al millar. En caso de llegar de arribada a algún puerto cercano por incidencias (combates, temporales) se repercutían los gastos de conducción y escolta hasta La Coruña. El Reglamento de Libre Comercio supuso una rebaja en estos gastos, dejándolos en un $8 \%$ aproximadamente.

42 Ibídem. El 20 de julio Manuel de Basavilbaso escribía desde Buenos Aires: “...luego que recibí la expresada providencia la hice extender al comercio por algunos Amigos..."

43 Sin embargo, siempre era posible que alguno no la hubiese recibido, por lo que Madariaga, sabedor de la solvencia económica de los preceptores, llegó a proponer que se les emitiera un recibo interino para no retrasar el percibo del dinero: "Los muchos años que há que me hallo en este destino me han hecho tener un pleno conocimiento de los Individuos de este Comercio..." AGI, Correos, 373A. ${ }_{44}$ AGI, Correos, 373B. Podemos encontrar en este legajo varios ejemplos al respecto.

45 AGI, Correos, 373A y B. En La Coruña el contrato con los Maragatos conductores se firmó el 3 de febrero de 1777, a tres octavos por ciento en plata y un cuarto por ciento en oro, con orden al Gobernador o Comandante para que tuviesen el auxilio necesario. Las conducciones requerían importante aparato. El envío de 10.738.941 reales de vellón para Madrid y Cádiz, más 500.000 reales producto de la Administración de La Coruña ponían en marcha, en marzo de 1785, dos divisiones de caballerías, de 42 unidades cada una, acompañadas de la correspondiente escolta.

46 Ibídem.

47 Para conocer otros aspectos del funcionamiento del Banco de San Carlos puede consultarse TEDDE DE LORCA, Pedro: "Fuentes para el estudio de la Banca en el Siglo XVIII: los fondos del Banco nacional de San Carlos",Separata de Actas del segundo Congresos sobre archivos de entidades privadas, Madrid, 1986.
} 


\begin{tabular}{|l|l|l|r|r|}
\hline \multicolumn{5}{|c}{ CUADRO IV: Caudales llegados a La Coruña } \\
\hline \multirow{2}{*}{ Año } & \multicolumn{1}{|c|}{ MES } & BARCO & \multicolumn{1}{c|}{$\begin{array}{c}\text { a Cádiz } \\
\text { R. vellón }\end{array}$} & $\begin{array}{c}\text { A Madrid } \\
\text { R.vellón }\end{array}$ \\
\hline $\mathbf{1 7 7 5}$ & Octubre & Tucumán & 873.373 & 57.010 \\
\hline $\mathbf{1 7 7 6}$ & Diciembre & Cantabria & 1.681 .792 & 129.015 \\
\hline $\mathbf{1 7 7 6}$ & Octubre & Tucumán & 1.338 .561 & 198.081 \\
\hline $\mathbf{1 7 7 6}$ & Junio & Infanta & 1.322 .910 & 164.587 \\
\hline $\mathbf{1 7 7 6}$ & Marzo & Diana & 313.240 & 191.125 \\
\hline $\mathbf{1 7 7 6}$ & Enero & Cantabria & 786.375 & 83.400 \\
\hline $\mathbf{1 7 7 6}$ & Febrero & Patagón & 621.181 & 65.640 \\
\hline $\mathbf{1 7 7 7}$ & Abril & Diligencia & 560.566 & 53.224 \\
\hline $\mathbf{1 7 7 7}$ & Enero & Diana & 141.062 & 6.000 \\
\hline $\mathbf{1 7 7 7}$ & Marzo & Quirós & 118.540 & 6.750 \\
\hline $\mathbf{1 7 7 8}$ & Diciembre & Cantabria & 2.321 .018 & 366.633 \\
\hline $\mathbf{1 7 7 8}$ & Julio & Princesa & 340.592 & 191.175 \\
\hline $\mathbf{1 7 7 8}$ & Octubre & El Rey & 1.982 .277 & 211.126 \\
\hline $\mathbf{1 7 7 8}$ & Octubre & Tucumán & 1.001 .815 & 75.720 \\
\hline $\mathbf{1 7 7 9}$ & Septiembre & Tucumán & 1.604 .140 & 244.117 \\
\hline $\mathbf{1 7 7 9}$ & Septiembre & Infanta & 1.785 .767 & 872.540 \\
\hline $\mathbf{1 7 7 9}$ & Agosto & Princesa & 3.042 .115 & 651.580 \\
\hline $\mathbf{1 7 7 9}$ & Marzo & Diana & 3.123 .996 & 217.598 \\
\hline $\mathbf{1 7 7 9}$ & Mayo & Diligencia & 2.580 .838 & 164.666 \\
\hline & & & 25.540 .158 & 3.949 .987 \\
\hline TOTAL & & & $86 \%$ & $14 \%$ \\
\hline
\end{tabular}

de las mismas en Madrid o en Cádiz ${ }^{48}$. El sistema resultaría ser igual de costoso que la utilización de los Maragatos conductores debido a las comisiones cobradas por el Banco, pero una vez concluido el recuento del efectivo llegado en los distintos paquebotes se recibía una letra por su importe, lo que resultaba de una gran comodidad y ligereza.

Tampoco con esta solución dejaron de producirse algunas incidencias. En junio de 1786 el Banco intentaba pagar en Cádiz con vales reales, a lo que se opuso rotundamente el Comercio. En septiembre de 1788 debió solicitarse seriamente que los pagos se realizaran en pesos fuertes y oro en cordoncillo:

Varios vecinos de esta ciudad interesados en los caudales...se me han quejado de que haciendo sus registros en moneda de plata u oro de cordoncillo, se les entregan aquí varias partidas en la menuda de pesetas, reales de plata, columnaria de cinco reales, de a dos y medio, y uno, y quartillo; en lo que se les sigue considerable perjuicio y engorro, no siendo poco el que causa a esta oficina en el recibo de dicha moneda menuda y quebrada de la tesorería del Banco nacional, y en el requento para la entrega y pago con la misma a los interesados ${ }^{49}$.

\footnotetext{
48 AGI, 373A. Fechada en 20 diciembre de 1785. "Mui Sres. Nuestros: Don Pedro Bernardo Casamayor ha hecho presente a la Junta, que trató ayer con VSS:

$1^{\circ}$ ) Que el Banco tomará en La Coruña todas las cantidades que VSS. tengan a bien hacer entregar a su comisionado en aquel Puerto. $2^{\circ}$ ) Que el Banco hará la entrega de las cantidades que perciba dicho Comisionado, con la rebaja de $1 / 4 \%$, sea en Madrid en efectivo, sea en letra a la vista, y a la par sobre Cádiz.

La Junta haviendo aprobado este trato ha dispuesto se lo participemos a VSS., como lo hacemos, y para formalizarlo, se han de servir VSS. darnos aviso de su conformidad, pasando las órdenes correspondientes a La Coruña a fin de que se entreguen los caudales que VSS. dispongan a nuestro comisionado Don Pedro $\mathrm{M}^{\mathrm{a}}$ de Mendinueta. Nuestro Señor guarde a VSS. muchos años. Firman por el Banco Nacional el marqués de Tolosa y Casamayor, como Directores generales de Giro."

49 AGI, 373A. Juan Nieto desde Cádiz, a 15 de septiembre de 1788.
} 
Las cantidades destinadas a Cádiz se hacían llegar mediante un efecto emitido por los directores de la Entidad financiera contra la caja de descuentos de la misma en dicha plaza, endosada a favor del Administrador gaditano por el Tesorero General de la Renta. Alternativamente se podía utilizar una carta de libranza contra fondos de la Renta existentes en el Banco. En ambos casos el pago se efectuaba a los interesados como habitualmente, previa entrega del conocimiento firmado. Pero con anterioridad a la fecha en que el Banco de San Carlos asumía el compromiso referido, y evitando el traslado físico del efectivo, consta que se utilizaban los servicios financieros de los Cinco Gremios Mayores de Madrid, a través de su Delegación en Cádiz ${ }^{50}$ o se aprovechaba la intermediación del Banco a través de los deudores de éste, de forma que la Entidad libraba en Madrid y a favor del Tesorero principal de Correos y Postas letras que deberían pagar en Cádiz algún obligado de la misma y ser cobrada por el Administrador de Correos de la Plaza, a cuya orden se endosaba ${ }^{51}$.

En la misma línea, se producían abonos en cuenta a importantes casas comerciales gaditanas en la Caxa general de la Entidad financiera de Madrid. Cantidad que deberían poner en Cádiz a disposición de la Administración de Correos ${ }^{52}$. El beneficio era mutuo: Correos disponía de dicho efectivo en Cádiz y los comerciantes, que probablemente dispondrían de caudales recibidos a través de algún barco, mercante o de guerra, llegado a la Plaza, tenían el abono en su cuenta con algún interés añadido y con facilidad para hacerlos llegar a otros destinos, nacionales o extranjeros.

\section{Utilización de la Administración de Cádiz para servicios varios}

No sólo se utilizaba la Administración gaditana para los servicios que hasta ahora hemos reseñado. También se recurría a ella para efectuar cobros o pagos en la ciudad relacionados con las actividades de los Correos Marítimos o Terrestres. Conceptos como pasajes de ciertos funcionarios o reparaciones de paquebotes efectuadas en América originaban recibos y cartas de pago a favor o en contra de la Tesorería de Correos y se justificaban en la contabilidad general de la Administración ${ }^{53}$.

La situación privilegiada de Cádiz, por sus contactos con las élites comerciales de ambas orillas, se aprovechaba para recabar todo tipo de información. Datos económicos sobre los fletes y los derechos de los géneros y pasajeros que desde aquel puerto se embarcaban para América. Informes sobre palmeo de los cajones de envíos de mercancías ${ }^{54}$. Encargos de compras de medidas contrastadas para ser utilizadas en La Coruña y de planos de navegación a Buenos Aires, a realizar en la Academia de Pilotos de Cádiz ${ }^{55}$. En febrero de 1768 el Administrador era interrogado sobre la existencia de fábricas de lonas en la zona. En el año 1769 avisaba de la existencia de barcos argelinos próximos a Gibraltar, que pudieran resultar peligros para la navegación de los paquebotes. En 1780 proponía listas de naves apresadas, que podían ser utilizadas para el servicio de Correos, y en 1783 realizaba el mismo servicio relacionando las embarcaciones de la Armada que, habiendo servido en el bloqueo de Gibraltar, estaban a la venta en el puerto de Cádiz ${ }^{56}$. Además de ello, continuamente se suministraban noticias sobre naves, mercantes o de guerra, que llegaban al puerto gaditano, indicando los días que habían utilizado en su navegación, mercancías que portaban, incidencias de los viajes, llegadas de flotas, y otros muchos datos de indudable utilidad en los centros de poder madrileños.

Y, sobre todo, resulta innegable la utilización de Cádiz como centro financiero y de actividades económicas ligadas al comercio. En septiembre de 1780 se les consulta sobre precios de seguros. El Administrador Madariaga parecía conocer con soltura este importante sector:

\footnotetext{
AGI, Correos, 373A.

51 AGI, Correos, 373B. En numerosos ejemplos se evidencia la capacidad económica de la ciudad de Cádiz. El 26 de septiembre de 1785 los Directores de Giro del Banco Nacional se dirigían a los Directores Generales de la Renta: “...deseando complacerles tendrán pronta la libranza de diez millones a la vista sobre la Caja de Descuentos de Cádiz... sobre Barcelona no es posible franquearla por carecer allí de fondos..."

52 AGI, Correos, 373A.

Ibídem.

AGI, Correos, 369A.

Ibídem. El Director de la Academia le contesta que necesitaba orden expresa del Bailio Julián de Arriaga

AGI, Correos,369 A y B, 432 A. Noticias varias extraídas de correspondencia con Directores Generales.
} 
...En embarcaciones rusas de San Petersburgo, en el supuesto de que hayan de venir al Ferrol, o a este puerto de Cádiz, y bajo la circunstancia de que lo que se asigne no sea prohibido de navegarse a Puertos de Potencias beligerantes, podrá asegurarse aquí sobre el premio de 20 1/4 \% a todos riesgos; y si se excluyen los de apresamiento, detención, y gastos anexos a esto, dejando sólo los riesgos ordinarios del Mar, se aseguran sobre un 81/4\%. Advirtiendo que en cualquiera embarcación de bandera neutra, menos la holandesa, se hará el seguro en iguales términos a los expresados ${ }^{57}$.

Igualmente se utilizaba la Plaza gaditana para la compra de letras en divisas, destinadas al pago de materiales provenientes del extranjero ${ }^{58}$, aprovechando la concurrencia en la ciudad de delegaciones de importantes comerciantes extranjeros ${ }^{59}$.

En 1802 los Correos Marítimos pasaron a depender de la Real Armada, situación que se prolongó hasta 1827. Desde esta fecha hasta 1851 se hizo cargo de ellos la Empresa de correos marítimos de la Habana. Posteriormente, hasta 1861, el servicio se cubrió indistintamente por barcos de vapor, de la Armada y particulares, y desde entonces, hasta la pérdida total de las colonias, por la Compañía Transatlántica Española ${ }^{60}$.

\section{A título de conclusión}

Resulta obligado reafirmar el inicio de nuestra exposición en cuanto al reconocimiento de la vital importancia de la rama de comunicaciones desde los puntos de vista político, administrativo, comercial, económico y social. Así lo entendieron los hombres, situados en elevadas cotas de poder, que gestionaron los Correos Terrestres y Marítimos entre 1764 y 1802.

Cádiz y su Administración tuvieron un especial protagonismo en el desarrollo de ambos. Aún cuando no tuviese establecida en esta ciudad la cabecera del contacto con América, que correspondió a La Coruña, si supuso alternativa de significada cuantía, por el elevado número de barcos, mercantes y de guerra, que portaron correspondencia en circuito complementario a los oficiales paquebotes.

Pero, sobre todo, porque era destino obligado de las remesas de oro y plata enviadas desde la otra orilla del Atlántico a los hombres de negocios gaditanos y porque a través de su puerto se recibieron cuantiosos recursos de las Administraciones americanas con destino a los Directores de la Renta.

Y, por último, de forma señalada, porque la utilización de los contactos, la obtención de información privilegiada, la captación de recursos económicos y la resolución de problemas financieros a través de Cádiz y su Administración de Correos son signos de la vitalidad de una ciudad que vivía su momento de esplendor. Todo ello nos ayuda a comprender el protagonismo de los hombres que la comunicaron con su entorno, próximo y lejano.

\footnotetext{
57 AGI, Correos, 459B.

58 Para suministrar a los buques Correos era necesaria la compra de lonas, cáñamos y brea procedentes de Holanda, Rusia, Inglaterra y otros orígenes.

59 AGI, Correos, 371B. Como ejemplo expondremos las necesidades surgidas en 1796, en complicada coyuntura bélica. El 21 de octubre conseguía Madariaga enviar cinco letras que sumaban aproximadamente 8.945 florines, giradas por la casa de los Sres. Bohol Hermanos, del Comercio de Cádiz: "que es de las de más crédito y seguridad." El cambio había resultado a 93 florines por ducado en efectivo, habiendo satisfecho por ellas 79.879 reales y 22 maravedíes de vellón. Dos de los efectos estaban librados por Bohol Hermanos a su propio nombre, contra los Señores Weddik \& Wendel, de Ámsterdam. Aparecen endosadas a los Directores Generales de la Renta por valor recibido del Conde de Torre Alegre. Las otras tres, libradas en Sevilla por Casamayor, eran pagaderas en Ámsterdam por Jacobi de Bronsvik, y habían sido libradas a la orden de Francisco Crespo, que las endosó a Juan Segalas, que las endosó a los Hermanos Bohol, que a su vez las endosaron a la Renta de Correos.

El 28 de octubre enviaba otra remesa, esta vez de nueve letras, por valor de algo más de 14.941 florines, por las que debió pagar 134.867 reales y 26 maravedíes de vellón. Algunas de ellas libradas por Guillet a cargo de Kantalaaret, otras libradas por Acqueroni a cargo de Busti y Cía. Todas sobre Ámsterdam y todas a la orden de Butler, cuya casa se tenía por sólida. En estos efectos consta en las copias el endoso (no firmado) a los Sres. Courtian Echenique, acreedores de la Renta.

60 Ver al respecto GARAY UNIBASO, Francisco: Los Correos...op. cit.
} 